\title{
COVID-19 Pandemic and Orthopaedic Surgeries: Hurdles and Hindrances
}

\author{
Mohammad Umar Mumtaz ${ }^{1} \quad$ Nadeem Ali ${ }^{1} \quad$ Altaf Ahmad Kawoosa ${ }^{1}$
}

${ }^{1}$ Department of Orthopaedics, Government Medical College, Srinagar, Jammu and Kashmir, India

Int J Recent Surg Med Sci 2021;7:1-2.

It has been rightly said that surgeons are talented, driven, and their hearts touched with fire.

For a surgeon, an operating room is no less than a place of worship, where he/she buds into a surgical craftsperson. For any surgical subspecialty an operating theater is a cornerstone on which its foundation is laid. ${ }^{1}$ One cannot imagine any of the surgical subspecialties without surgical procedures being performed.

When we look back, the year 2020 has shaken all the surgical specialties around the globe. And all this drama started since December 2019 with the outbreak of a novel human pneumonia from the city of Wuhan in China. The novel virus responsible for this outbreak belongs to coronavirus family and was subsequently designated as SARS-CoV-2 and the disease named as coronavirus disease 2019 (COVID-19). Subsequently the virus had a global spread and in March 2020 it took shape of a pandemic. ${ }^{2}$ The disease being highly contagious did not spare any country in the world. Presently there is no approved antiviral drug therapy available for this deadly virus and the vaccination still is in trial phase. ${ }^{3}$ Each country had adopted certain stringent protocols and lockdowns to prevent the transmission and halt the disease in the community but met with failures; the second wave of the disease has already arrived in some countries and poses a threat to others in near future. ${ }^{4,5}$

The pandemic has not only shaken the world economy and brought about a humanitarian catastrophe but affected every sector-the worst hit was the health care system which collapsed under the burden of this contagion. ${ }^{4}$ The surgical specialties reduced the quantum of their surgical procedures by stopping the elective surgical procedures. In orthopaedics, wherever feasible, a conservative approach was even chosen for the trauma cases. ${ }^{6}$ At our institute, we followed a dictum "it is better to treat a nonunion or a malunion at a later date rather than to expose the patients and the hospital staff to this deadly virion." Orthopaedic
Address for correspondence Nadeem Ali, MS, Department of Orthopaedics, Government Medical College, Mughal Mohalla, Lalbazar, Srinagar 190023, Jammu and Kashmir, India (e-mail: drnadeeem@gmail.com).

specialty utilizes high-speed tools and gadgets like power drills, oscillating saws, and burrs that generate aerosols and droplets, exposing the surgeon and the theater staff to the virus. ${ }^{7}$ Besides these measures, the contact was minimized by keeping minimal staff on duty, discharging the patients as soon as possible, restricting the admissions to only emergency and trauma cases that deserved observation or a surgical intervention, and reducing the patient's follow-up hospital visits by encouraging the telephonic follow-ups (-Fig. 1).

Slowly, throughout the globe, the elective orthopaedic and trauma surgeries are resuming but under a protocol to prevent the spread of the disease. ${ }^{8}$ We have also restarted elective orthopaedic procedures at our institute under a similar type of preventive protocol which includes screening of the patients at the time of admission for the SARS-CoV-2 by utilizing reverse transcription-polymerase chain reaction (RT-PCR) testing. But we are facing many problems and difficulties that make us go on to back foot as far as elective procedures are concerned. Some of these difficulties can be enumerated as follows:

- The elective surgeries that were planned to be performed in the last 8 months have created a backlog and need to be addressed and re-dated on priority basis.

- The patients who could not attend the hospital in view of the lockdown and COVID-19 fear are flocking now, which has increased the burden on the outpatient services as well as the risk of transmission of the virus among the patients and to the hospital staff.

- It takes 24 hours for the RT-PCR results to be available at our institute and till then we need to isolate the admitted patients in separate isolation wards.

- In case an admitted patient turns out to be positive for SARS-CoV-2, all the patients isolated in the same ward are considered infected unless proved otherwise. And all these patients need to be sent to home quarantine. published online

March 1, 2021
DOI https://doi.org/

$10.1055 / \mathrm{s}-0041-1725232$ ISSN 2455-7420.
(O2021. Medical and Surgical Update Society.

This is an open access article published by Thieme under the terms of the Creative Commons Attribution-NonDerivative-NonCommercial-License, permitting copying and reproduction so long as the original work is given appropriate credit. Contents may not be used for commercial purposes, or adapted, remixed, transformed or built upon. (https://creativecommons.org/licenses/by-nc-nd/4.0/).

Thieme Medical and Scientific Publishers Pvt. Ltd. A-12, 2nd Floor, Sector 2, Noida-201301 UP, India 


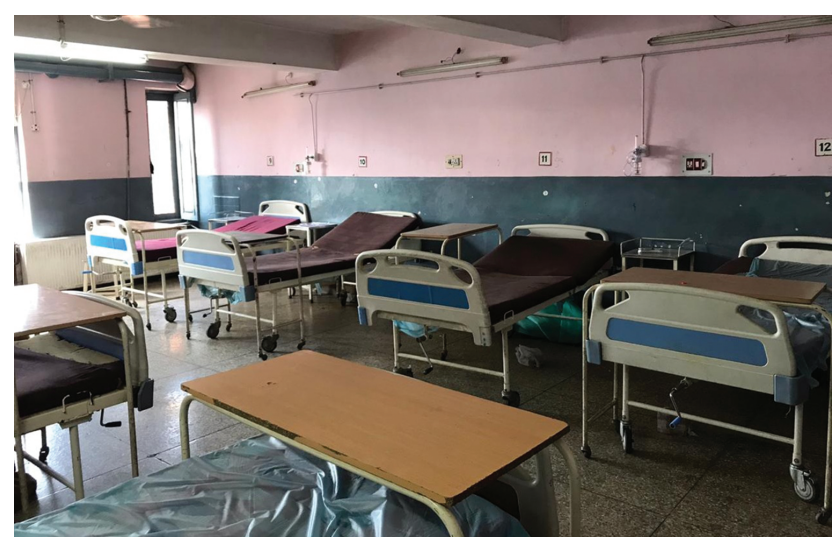

Fig. 1 Vacant beds in one of our orthopaedics wards during COVID-19 lockdown.

- The false-negative rate of RT-PCR ranges from 2 to $39.8 \%{ }^{9}$ So theoretically there is every potential of missing some patient which may became a potential threat for other patients and the hospital staff.

- The anesthesiologists have been in the frontline in this war against COVID-19. ${ }^{10}$ Due to limited availability of anesthesiologists, the outdoor preanesthetic checkups at our institute have been stopped. This has lead to unnecessary delays in the surgical procedure on patients with comorbidities, thus increasing their hospital stay and risk of exposure to the virus.

- In developing countries like ours, where hospital infrastructure is poor and masses are uneducated, there is no barrier for the attendants and relatives of the patients to visit the hospital and they can be potential spreaders of the COVID-19 in the hospital.

- Those admitted patients whose surgery is delayed beyond one week are retested for COVID-19. And there have been cases that have tested positive for the virus on retesting after one week, which makes us rethink if elective surgeries should be restarted.

- Some patients after surgical intervention have turned positive after being retested either because of some symptoms or due to other patients in the vicinity turning positive.

- Majority of the patients that have been labeled positive for COVID-19 after hospital admission have been asymptomatic for the disease.

- Since the attempts at starting of elective orthopaedic procedures, more and more orthopaedic doctors, especially the residents, are turning positive for COVID-19 at our institute.

- Use of personal protective equipment (PPE) while operating in the pandemic is a necessity. And it is well known that the use of PPE while operating makes the surgeon uncomfortable and increases fatigue, which may interfere with surgical performance. ${ }^{11}$ As operating orthopaedic surgeons we have ourselves noted an increase in the operative time when we operate wearing PPE. Besides, fogging of the facial protective gear, difficulty in communication with the assistants and scrub nurse, and excessive sweating with use of PPE further interferes with our surgical performance. At times we feel difficult to scrub on for a second case.

Considering these difficulties we are currently facing with our attempts to restart the elective orthopaedic procedures in our institute, there is a need to rethink this step of restarting such procedures in developing countries where the government hospitals are overburdened. Elective procedures should be prioritized as per need and the number of admissions and procedures kept minimum, to limit the number of patients admitted at a particular time in the hospital.

\section{Conflict of Interest}

None declared.

\section{References}

1 Kavic MS. Surgery, passion, and the medical student. JSLS 1999;3(3):169-170

2 Liu YC, Kuo RL, Shih SR. COVID-19: the first documented coronavirus pandemic in history. Biomed J 2020;43(4):328-333

3 Shereen MA, Khan S, Kazmi A, Bashir N, Siddique R. COVID-19 infection: origin, transmission, and characteristics of human coronaviruses. J Adv Res 2020;24:91-98

4 Ghosh J. A critique of the Indian government's response to the COVID-19 pandemic. J Ind Bus Econ 2020;11:1-12

5 Saito S, Asai Y, Matsunaga N, et al. First and second COVID-19 waves in Japan: a comparison of disease severity and characteristics. J Infect 2020;S0163-4453(20)30693-9

6 Ali N, Kawoosa AA. Has "conservative orthopaedics" re-emerged as a new branch in the COVID-19 pandemic? Curr Orthop Pract 2020;32(6):620

7 Geevarughese NM, Ul-Haq R. Aerosol generating procedures in orthopaedics and recommended protective gear. J Clin Orthop Trauma 2020

8 Parvizi J, Gehrke T, Krueger CA, et al; International Consensus Group (ICM) and Research Committee of the American Association of Hip and Knee Surgeons (AAHKS). Resuming Elective Orthopaedic Surgery during the COVID-19 pandemic: guidelines developed by the International Consensus Group (ICM). J Bone Joint Surg Am 2020;102(14):1205-1212

9 Alcoba-Florez J, Gil-Campesino H, Artola DG, et al. Sensitivity of different RT-qPCR solutions for SARS-CoV-2 detection. Int J Infect Dis 2020;99:190-192

10 Gupta B, Bajwa SJ, Malhotra N, Mehdiratta L, Kakkar K. Tough times and miles to go before we sleep-corona warriors. Indian J Anaesth 2020;64(Suppl 2) :S120-S124

11 Yánez Benítez C, Güemes A, Aranda J, et al; International Cooperation Group on PPE and Emergency Surgery. Impact of personal protective equipment on surgical performance during the COVID-19 pandemic. World J Surg 2020;44(9):2842-2847 